Hot-spot application of biocontrol agents to replace pesticides in large scale commercial rose farms in Kenya

Gacheri, Catherine; Kigen, Thomas; Sigsgaard, Lene

Published in:

BioControl

DOI:

10.1007/s10526-015-9685-0

Publication date:

2015

Document version

Publisher's PDF, also known as Version of record

Citation for published version (APA):

Gacheri, C., Kigen, T., \& Sigsgaard, L. (2015). Hot-spot application of biocontrol agents to replace pesticides in large scale commercial rose farms in Kenya. BioControl, 60(6), 795-803. https://doi.org/10.1007/s10526-0159685-0 


\title{
Hot-spot application of biocontrol agents to replace pesticides in large scale commercial rose farms in Kenya
}

\author{
Catherine Gacheri · Thomas Kigen • \\ Lene Sigsgaard $\mathbb{D}$
}

Received: 20 March 2014 / Accepted: 2 July 2015

(C) International Organization for Biological Control (IOBC) 2015

\begin{abstract}
Rose (Rosa hybrida L.) is the most important ornamental crop in Kenya, with huge investments in pest management. We provide the first full-scale, replicated experiment comparing cost and yield of conventional two-spotted spider mite ( $T e$ tranychus urticae Koch) control with hot-spot applications of the predatory mite Phytoseiulus persimilis (Acari: Phytoseidae) in large commercial rose greenhouses. Hot-spot treatments replaced acaricides except at high infestations and the two treatments were applied in seven greenhouses each. With the conventional treatment, acaricides were applied when T. urticae populations exceeded 250 motile individuals per plant based on scouting. Treatments with acaricides and $P$. persimilis were guided by weekly scouting and hot-spot treated greenhouses with infestations exceeding 1000 individuals $\mathrm{m}^{-2}$ (calculated as average mites/leaflet $\times$ average leaflets per plant)
\end{abstract}

Handling Editor: Arne Janssen.

C. Gacheri · T. Kigen

Dudutech -A Division of Finlays Horticulture Kenya

Limited, Kingfisher Farm,

P.O. Box 1927, Naivasha 20117, Kenya

e-mail: Catherine.Gacheri@finlays.net

L. Sigsgaard ( $\square)$

Department of Plant and Environmental Sciences, Faculty

of Sciences, University of Copenhagen, Thorvaldsensvej

40, 1871 Frederiksberg, Denmark

e-mail: les@plen.ku.dk were first blanket-treated with an acaricide to decrease infestations. Roses subjected to the hot-spot treatment had significantly lower T. urticae infestations compared with conventionally treated roses. In addition, significantly fewer high spider mite infestations were recorded in roses with the hot-spot treatment. The cost of pest management was significantly lower in the hotspot-treated greenhouses than in the conventional treatment. However, there was no significant difference in the number of harvested stems from the two treatments. It can therefore be concluded that acaricides can be replaced by $P$. persimilis hot-spot treatments in commercial cut rose production, effectively reducing pest management costs with no loss in crop yield.

Keywords Acari $\cdot$ Phytoseidae $\cdot$ Cost-benefit · Rose $\cdot$ Phytoseiulus persimilis $\cdot$ Tetranychus urticae

\section{Introduction}

Kenya is a major producer and exporter of horticultural commodities, flowers being the highest in volume and value of the exported horticultural products. The cut flowers industry is among the fastest growing sectors of the Kenyan economy, with revenues of approximately \$US 0.5 billion in foreign exchange (HCDA 2009) based on an exchange rate of 1 \$US $=80$ KES. Rose (Rosa hybrida L.) is the most 
important cut flower, amounting to $77 \%$ of the flower volume and $62 \%$ of the flower value in 2009 (HCDA 2009). A major proportion of rose production in Kenya takes place in large commercial greenhouses and in such greenhouses, pest infestations develop quickly, and the costs of pest control constrain rose production. The twospotted spider mite Tetranychus urticae Koch (Acari: Tetranychidae) is a highly important rose pest, often constituting the main expense in pest management budgets (Zhang 2003; van de Vrie 1985). The control of spider mites has been based mainly on the use of acaricides, resulting in pesticide resistance and accumulation of pesticide residues on the harvested products (Attia et al. 2013; Khajehali et al. 2011; Escudero and Ferragut 2005). In addition, acaricides are known to be highly toxic to farm workers, nontarget organisms and the environment (Znaor et al. 2005). The current demand for good agricultural practices by trading partners and consumers has influenced the choice of pesticides in crop production and many growers have opted for the use of biocontrol agents such as Phytoseiulus persimilis Anthias-Henriot (Acari: Phytoseiidae), which effectively reduces T. urticae populations in floricultural crops (Holt et al. 2007; Casey et al. 2007; Opit et al. 2004; Nicetic et al. 2001; De Vis and Barrera 1999) as well as other crops such as vegetables (Zhang 2003). P. persimilis is a specialized spider mite predator and feeds on all life stages of T. urticae and its populations build up rapidly when food is plenty and climatic conditions are favorable. However, it is difficult to establish and maintain when prey densities are low, so it is exclusively used for inundative biological control (Casey et al. 2007). Low pest tolerance by growers can therefore make successful introduction of biological control with $P$. persimilis in commercial production difficult (De Vis and Barrera, 1999). In Kenya, utilization of this predatory mite within commercial flower companies was initiated by Dudutech, a commercial producer of biocontrol agents since the late 1990s. Growers in Kenya usually release $P$. persimilis uniformly, based on spider mite density (Jacobson 1993). Tetranychus urticae moves slowly, but is easily dispersed by air, which leads to a patchy distribution of T. urticae in the crop (El-Laithy and Sawsan 2005), and areas of aggregation in the greenhouse become a source of its spread. Targeting these areas of aggregation, or hot-spots, could limit spread and build-up of T. urticae (Alatawi et al. 2011), thus effectively reducing exposure of workers and environment to acaricides and potentially reducing costs of spider mite control. In this study, we compare two strategies for spider mite control in commercial rose production with respect to mite control, cost of pest management and yield: a) uniform application of acaricides, i.e. the conventional treatment, and b) hotspot applications of $P$. persimilis, replacing acaricides except at high infestations.

\section{Materials and methods}

The study was conducted in commercial rose greenhouses on Kingfisher Farm at the shores of Lake Naivasha, Rift Valley province, Kenya $\left(0^{\circ} 47^{\prime} 60 \mathrm{~N}\right.$, $36^{\circ} 21^{\prime} 0 \mathrm{E}$ ), which lies at an altitude of $1800-2000 \mathrm{~m}$ above sea level. Within the farm, 14 plastic covered greenhouses were randomly selected, all with roses cultivated on raised beds in a hydroponic cultivation system. These greenhouses were part of the farm's commercial greenhouses and they continued to provide commercial flowers during the 30 weeks of trials, weeks 1-30, in 2011. In 2011, the Kingfisher farm weather station recorded a mean monthly temperature of $19 \pm 1.1^{\circ} \mathrm{C}$, an average monthly minimum temperature of $11^{\circ} \mathrm{C}$, an average monthly maximum of $27{ }^{\circ} \mathrm{C}$ and an annual precipitation of $814 \mathrm{~mm}$ (monthly range $3-133 \mathrm{~mm}$ ). All greenhouses were within a distance of $500 \mathrm{~m}$ from each other, hence had similar climatic conditions and in all greenhouses the crop was already well established before the start of the experiment with a density of eight plants $\mathrm{m}^{-2}$. The 14 selected greenhouses were from 4100 to $16,820 \mathrm{~m}^{2}$ large and had housed seven different rose varieties, each occupying two greenhouses (Table 1), and for each rose variety one greenhouse was used as a control (i.e. conventional treatment) and the other was used for the hot-spot treatment, and none of the varieties had known resistance to $T$. urticae or were known to have negative effects on $P$. persimilis. Treatments against $T$. urticae included the use of $P$. persimilis obtained from a commercial rearing unit at Dudutech, a subsidiary of Finlay Horticulture (K) LTD, and acaricides (Table 2). Dudutech is located within the Kingfisher farm where the trial was carried out, and produces $P$. persimilis commercially, so predators could be delivered one day after harvesting. 


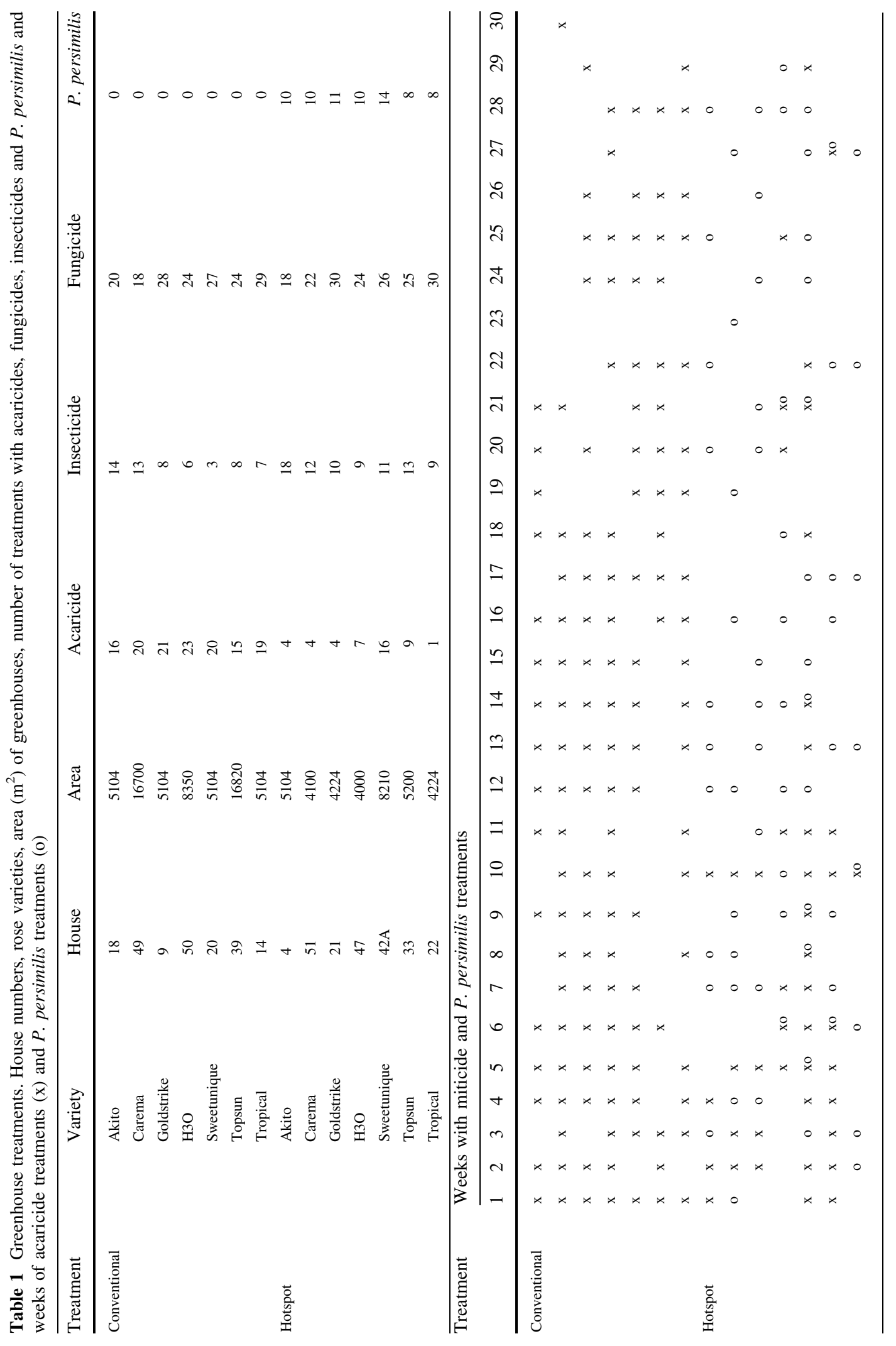


Table 2 Acaricides applied in the greenhouses

\begin{tabular}{|c|c|c|c|}
\hline Active ingredient & Trade name & Rate $\left(\mathrm{ml} \mathrm{l}^{-1}\right)$ & Management option \\
\hline $1 \%$ Milbemectin & Milbeknock $1 \%$ EC & 50 & Both \\
\hline Abamectin & Dynamec $1.8 \mathrm{EC}$ & 50 & Both \\
\hline Abamectin & Zoro TM 18 EC & 50 & Both \\
\hline Abamectin $2.0 \mathrm{~g}^{-1}$ & Abamite $2.0 \mathrm{Ec}$ & 30 & Both \\
\hline Alpha cypermethrin & Fastac $10 \mathrm{EC}$ & 30 & Conventional \\
\hline Bifenazate & Floramite $240 \mathrm{SC}$ & 40 & Hotspot \\
\hline Chlorfenapyr & Secure 36 SC & 50 & Conventional \\
\hline Clofentezene & Apollo $50 \mathrm{SC}$ & 30 & Hotspot \\
\hline Clofentezene $500 \mathrm{~g} \mathrm{l}^{-1}$ & Efentezine 50SC & 60 & Hotspot \\
\hline Etoxazole & Baroque 10SL & 50 & Hotspot \\
\hline Hexythiazox & Nissorun 10 EC & 50 & Hotspot \\
\hline Hexythiazox $100 \mathrm{~g}^{-1}$ & Hexygon $10 \% \mathrm{Ec}$ & 50 & Both \\
\hline Profenofos $400 \mathrm{~g}^{-1}+$ Cypermetrin $40 \mathrm{~g}^{-1}$ & Polytrin P 440Ec & 60 & Conventional \\
\hline Pyridaben & Dynomite $15 \mathrm{EC}$ & 90 & Conventional \\
\hline Pyridaben $200 \mathrm{~g}^{-1}$ & Pyrimite 200 EC & 80 & Conventional \\
\hline Spiromesifen & Oberon SC 240 & 50 & Conventional \\
\hline Tebufenpyrad & Oscar $200 \mathrm{EC}$ & 30 & Conventional \\
\hline
\end{tabular}

The column management option refers to whether the acaricide quoted was used in hot-spot treated greenhouses, in controls (conventional) or in both treatments

Phytoseiulus persimilis was applied as a hot-spot treatment using $200 \mathrm{ml}$ bottles each containing 2000 predators, with vermiculite as a carrier material to enable uniform distribution of the predators, and the bottle was rotated while sprinkling the contents on the crop, and before application, the number of plants each bottle would treat was calculated in order to reach a $P$. persimilis:T. urticae ratio of 1:10. Acaricides were applied as conventional treatment uniformly within the greenhouse and to safeguard flower production acaricides were allowed to be sprayed in every greenhouse irrespective of the treatment when $T$. urticae populations attained the acaricide action threshold level (i.e., 250 motile T. urticae per plant on average based on scouting data), as such an agreement was necessary for greenhouse managers to allow the conversion to hot-spot treatment in these greenhouses. Scouting and spraying followed the normal practice at the farm, and cost 0.14 and 0.18 $\mathrm{KES} \mathrm{m}^{-2}$ per week, respectively. Scouting that involved mite data recording was done once a week in every greenhouse and an additional weekly check was done by the scout for any upcoming pest and disease problems. Based on the scouting report, the production manager and the scout agreed on the spray plan, and if the T. urticae numbers were above threshold levels a conventional spray was decided, otherwise the number of $P$. persimilis to apply was calculated based on infestation levels in the identified hotspots, and application of pesticides or predators was done within the same week as the scouting.

Insecticides were applied as top spray, minimizing side-effects on predatory mites which were protected in the lower canopy. The equipment for spraying was a central pesticide application system where pesticide preparation is done in a mixing area and then distributed via a system of pipes, and pesticides were applied using a handheld gun which breaks the spray into small droplets, and directed at the foliage. The acaricide was applied uniformly within the greenhouse and to reduce negative effects of pesticides on $P$. persimilis, they never were applied earlier than 3 days after an acaricide/ insecticide treatment. The T. urticae infestations in the greenhouses were natural, and in all the greenhouses, another predatory mite Neoseiulus californicus (McGregor) (Acari: Phytoseiidae) occurred naturally. Other pests requiring control included thrips (Frankliniella occidentalis (Pergande)), which were present in both hot-spot treated and conventional greenhouses, and aphids (Macrosiphum rosae (L.)), which were most 
abundant in hot-spot greenhouses. Acaricides used in the trial were chosen based on a resistance management strategy set by Insecticide Resistance Action Committee (IRAC 2014) and are listed in Table 1.

Hot-spot plants, defined as plants on which scouting had identified a total of more than 40 motile mites on three leaflets, one from the base, the middle, and the top of the plant, were marked with a thin, yellow polythene strip to guide the $P$. persimilis application. Hot-spots were treated within $24 \mathrm{~h}$ of scouting and to ensure efficiency of mite management with $P$. persimilis the treatment included all plants within an area of $2 \times 1 \mathrm{~m}$ of a flower bed, with the hot-spot tagged plant in the centre, equivalent to eight plants. The number of $P$. persimilis to apply was chosen so the $P$. persimilis:T. urticae ratio was $1: 10$, and application was focused on the affected plant(s), such that surrounding, less infested plants in the $1 \times 2 \mathrm{~m}$ area received fewer mites. Hot-spots sometimes persisted for more than a week, and if the $P$. persimilis density was less than half of the T. urticae density after one week, additional $P$. persimilis were added.

The hot-spot treatment was introduced gradually, and the study covered the period after which all seven greenhouses assigned to this treatment had been converted. Sampling was done weekly, and each greenhouse was divided into 20 scouting stations, each station consisting of four flower beds, each $1 \mathrm{~m}$ wide and $100 \mathrm{~m}$ long, so the total area of a scouting station was $400 \mathrm{~m}^{2}$. Ten plants were randomly selected from these scouting stations and marked, yielding 200 plants to be scouted within each greenhouse. All motile stages of $T$. urticae and $P$. persimilis were counted in situ with a lens of $\times 10$ magnification on three leaflets per plant, one from the canopy base (shoots bent over beds), one from the middle of the canopy (area between base and top) and one from the top (flowering shoots), amounting to a total of 600 leaflets per greenhouse. The mean number of leaflets on a plant was estimated based on a count of all leaflets in the top, middle and lower canopy of four plants and for every plant scouted, one leaflet was picked from the base canopy, middle canopy and top canopy. $T$. urticae, $P$. persimilis motiles and $N$. californicus motiles (combined adults and juveniles) were then counted using a magnifying lens, and recorded on the scouting form. Scouting was always done in the same order, and results were recorded in the same order in the scouting form, so that comparisons on pest build up and establishment of the predatory mites could be done in each specific station. No other predatory mite species were observed, and apart from the T. urticae and $P$. persimilis counts data on the weekly cost of each management option and the weekly yield in terms of number of harvested rose stems was recorded and verified by the greenhouse managers and the scouts based on purchase of pesticides, $P$. persimilis abundance, and harvested stems.

\section{Data analysis}

Means of pest and predator abundances per leaflet in hot-spot treated greenhouses and in conventional greenhouses for the 30-week period of study were compared using ANOVA (Proc MIXED) (SAS Institute Inc 2008) and when necessary data were transformed prior to analysis to meet the requirements for a parametric analysis. A repeated measures analysis on weekly counts was conducted to identify any trends separating the two treatments, using a general mixed linear model (Proc MIXED) (SAS Institute Inc 2008), and because the same greenhouses were measured across time a repeated measures covariance structure was used. Treatment means were separated with a $t$ test at a $95 \%$ level of significance, and fixed effects were treatment (hot-spot or conventional), variety (seven varieties) and week (30 weeks). The full model included all interactions of fixed effects, and greenhouses together with varieties were included as a random factor. The full model was reduced backwards by removing higher-order non-significant interactions, and only retaining significant interaction effects. The same modeling approach was used for weekly costs of acaricides, cost of $P$. persimilis, and yield in terms of harvested rose stems, which were also analyzed using ANOVA (Proc MIXED). For these datasets, a repeated measures analysis was also conducted to identify any trends separating the two treatments (Proc MIXED) (SAS Institute Inc 2008), and for these datasets full models including all interaction effects were also reduced backwards until only significant interaction effects were retained.

\section{Results}

The average number of $T$. urticae per leaflet in hotspot treated greenhouses was 3.4 times lower 

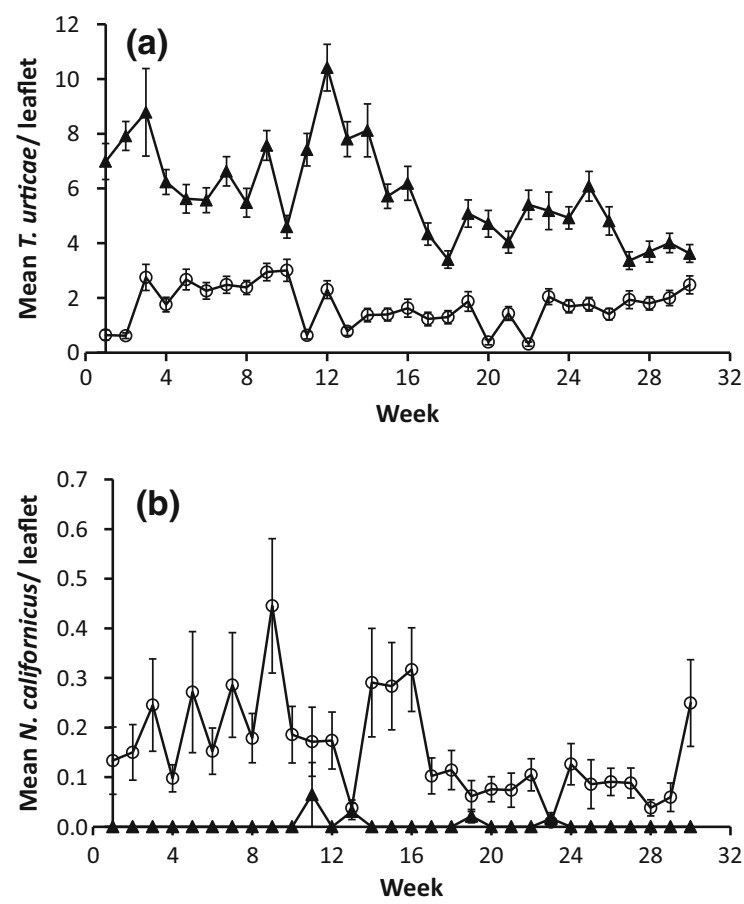

Fig. 1 Weekly mean number $( \pm$ SE) of the motile stages of a $T$. urticae and $\mathbf{b} N$. californicus per leaflet in hot-spot treated greenhouses (unfilled circle) and in conventional treated greenhouses (filled triangle)

(mean $\pm \mathrm{SE})(0.57 \pm 0.02)$ than in conventionally treated greenhouses (control) $(1.93 \pm 0.04)$ (Fig. 1a) and there was a highly significant interaction effect of treatment $\times$ week $\left(\mathrm{F}_{29,406}=2.3, \mathrm{P}<0.0001\right)$ on $T$. urticae numbers (log-transformed). P. persimilis was only found in hot-spot treated greenhouses $(0.08 \pm 0.005$ per leaflet $)$, while the naturally occurring predatory mite $N$. californicus was significantly more abundant in hot-spot treated greenhouses $(0.05 \pm 0.004$ per leaflet $)$ than in conventional greenhouses $(0.001 \pm 0.0004$ per leaflet) (Fig. 1b) $\left(\mathrm{F}_{1,7}=8.8, \mathrm{P}=0.02\right)$ (Proc MIXED, SAS Institute Inc 2008). Hot-spot treated greenhouses had on average $6.0 \pm 0.29$ hot-spots per week of which $2.1 \pm 0.3$ hot-spots per week were treated, by applying a mean of $9438.1 \pm 662.3 P$. persimilis per hotspot. The remaining hot-spots had an adequate proportion of $P$. persimilis and were not treated. The mean number of $P$. persimilis used was $32.3 \%$ lower in the last 15 weeks of the study compared to the first 15 weeks $\left(\mathrm{F}_{1,6}=9.1, \mathrm{P}=0.023\right)$.

Treatment frequency of acaricides was three times lower in hot-spot greenhouses $(0.21 \pm 0.03$ treatments
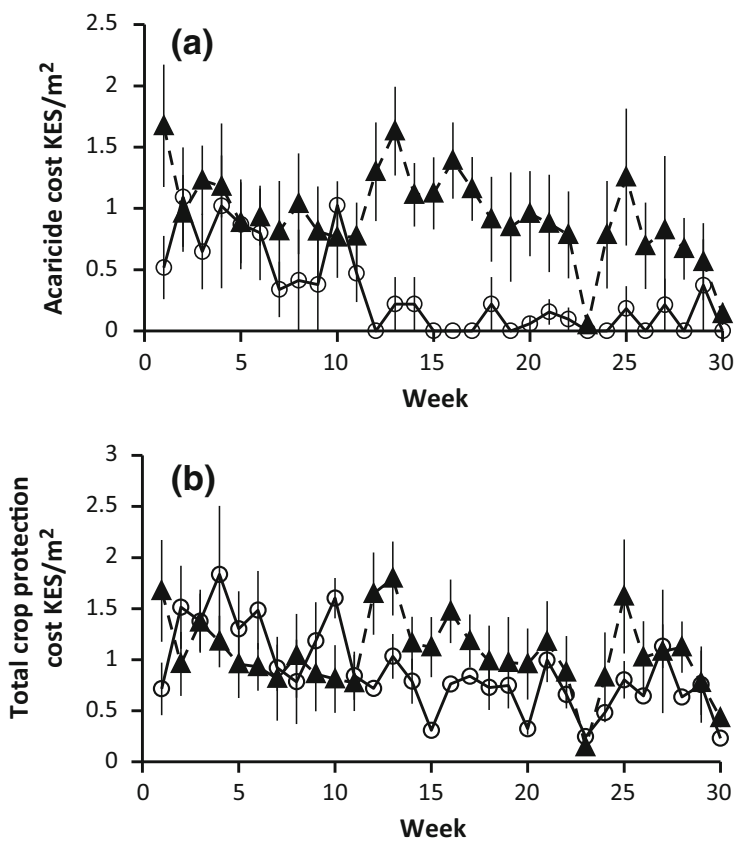

Fig. 2 Weekly mean costs (KSH) per $\mathrm{m}^{2}( \pm \mathrm{SE}$ ) of a acaricide treatments and $\mathbf{b}$ the total cost of crop protection (acaricide, insecticide and $P$. persimilis) in hot-spot treated greenhouses (unfilled circle) and in conventional treated greenhouses (filled triangle)

per greenhouse per week) than in conventional greenhouses $(0.64 \pm 0.03$ treatments per greenhouse per week) $\left(\mathrm{F}_{1,6}=35.8, \mathrm{P}=0.001\right)$. There was no difference in use of fungicides, while insecticide use was $28 \%$ higher in hot-spot greenhouses $(0.39 \pm 0.03$ treatments per greenhouse per week) than in conventional greenhouses $(0.28 \pm 0.03$ treatments per greenhouse per week) $\left(\mathrm{F}_{1,6}=9.6, \mathrm{P}=0.021\right)$.

Cost of acaricides and other plant protection products

Amongst all pesticides, acaricide applications resulted in the highest costs, other costs were fungicides and insecticides (Fig. 2). Fungicide costs were not significantly different between treatments (data not included).

Acaricide cost was three times lower in hot-spot treated greenhouses $\left(0.31 \pm 0.05 \quad \mathrm{KES} \mathrm{m}^{-2}\right) \quad(1$ $\$ \mathrm{US}=108 \mathrm{KES}$, Kenyan Shilling) compared with the conventionally treated greenhouses $(0.94 \pm 0.07$ KES $\mathrm{m}^{-2}$ ). In addition, there was a significant interaction effect of treatment and week (PROC MIXED) 
$\left(\mathrm{F}_{29,406}=1.8, \mathrm{P}<0.006\right)$, reflecting that in hot-spot treated greenhouses a decrease in treatments with time was observed, with only $20 \%$ of 45 acaricide treatments occurring in the last half of the 30 week study period. In conventional greenhouses, such a decrease was not evident, as $41 \%$ of the 134 acaricide treatments occurred in the last half of the study. The production cost of $P$. persimilis was $15.82 \pm 0.06$ KES per $1000 P$. persimilis, and in the hot-spot treated greenhouses, the average weekly cost was $0.38 \pm 0.04$ KES $\mathrm{m}^{-2}$. The cost of controlling mites (acaricide $+P$. persimilis) was only significantly correlated with week $\left(\mathrm{F}_{29,406}=2.71, \mathrm{P}<0.0001\right)$, with no difference in mite control costs between the two treatments. Scouting costs include the application of $P$. persimilis and any other biological control agents, and were the same in the two treatments, but personnel for spraying pesticides are hired for the whole farm so savings from reduced time spent spraying in hot-spot greenhouses could not be analyzed.

\section{Yield effects}

Weekly yield in the 14 greenhouses was assessed as harvested stems $\mathrm{m}^{-2}$, and there were 4 plants $\mathrm{m}^{-2}$ in all greenhouses. In conventionally treated greenhouses, the mean weekly yield was $3.72 \pm 0.10$ stems $\mathrm{m}^{-2}$ and in hot-spot treated greenhouses $3.93 \pm 0.10$ stems $\mathrm{m}^{-2}$. There was a near significant main effect of treatment on yield in favour of hot-spot treatment $\left(\mathrm{F}_{1,413}=3.8, \mathrm{P}=0.053\right)$ and a significant effect of week $\left(\mathrm{F}_{29,413}=3.8, \mathrm{P}<0.0001\right.$ ) (Proc MIXED), reflecting that harvest varied among weeks.

\section{Pest control cost per harvested stem}

The cost of spider mite control (acaricides and $P$. persimilis) for producing one harvested stem was $27 \%$ less in the hot-spot treated greenhouses $(0.69 \pm 0.06 \mathrm{KES})$ than in the conventional greenhouses $(0.94 \pm 0.07 \mathrm{KES})$ with a highly significant main effect of treatment $\left(\mathrm{F}_{1,413}=10.8, \mathrm{P}=0.001\right)$ and a significant effect of week $\left(\mathrm{F}_{29,413}=1.6\right.$, $\mathrm{P}=0.021)$. The total pest control cost to produce one harvested stem (acaricides, insecticides and $P$. persimilis) was $17 \%$ less in hot-spot treated greenhouses $(0.88 \pm 0.07 \mathrm{KES})$ than in conventional greenhouses (1.06 $\pm 0.07 \mathrm{KES})$, with significant main effects of treatment $\left(\mathrm{F}_{1,7}=6.6, \mathrm{P}=0.037\right)$ and week $\left(\mathrm{F}_{29,406}=1.6, \mathrm{P}=0.034\right)$.

\section{Discussion}

We show that hot-spot treatments with $P$. persimilis are an effective method to reduce infestations of $T$. urticae on roses in commercial greenhouses, resulting in a low requirement for application of synthetic pesticides on an annual basis, and such acaricide application can be based on a monitoring schedule and mite action threshold levels. In contrast, continuous, though controlled, use of synthetic acaricides could not maintain $T$. urticae infestation at levels comparable with hot-spot application of $P$. persimilis. The decrease in acaricide treatments over time after the onset of hot-spot treatment is a general experience at the farm, and situations where few acaricide treatments are needed are normally achieved. There was also a decrease in the number of $P$. persimilis applied over time in the hot-spot greenhouses, and this indicates that our results to some extent represent a conversion period from acaricides to biological control for the hot-spot greenhouses, and that spider mite control using lower $P$. persimilis input can be achieved. More aphids were observed in hot-spot greenhouses, and may have caused the higher insecticide use. This is an undesirable effect and biological control agents are available which could replace insecticides against aphids. However, total use of acaricides and insecticides remained significantly lower in the hot-spot greenhouses, with a total of 9.1 treatments over the study period, compared to 13.8 treatments in the conventional greenhouses (Table 2).

Acaricide use for management of T. urticae is not only common in Kenyan commercial greenhouses, but also in other parts of the world (Bugeme et al. 2008; Knapp et al. 2006). However, T. urticae is known to develop resistance to most widely used acaricides (Goka 1998; Stavrinides et al. 2009; Khajehali et al. 2011; van Leeuwen 2011), leading to ineffective control.

We did not test for acaricide resistance in this study, but the lack of mite reduction in conventional greenhouses to levels below threshold limits may be an indication of resistance. Hence, year-round utilization of acaricides as a sole response to T. urticae may not offer long term control of the pest in protected cultivation. 
Our findings show that hot-spot management of $T$. urticae can significantly reduce the costs of rose production, thus providing an economic incentive for growers to change to this method of control, and this result is supported by an unreplicated experiment in an Austrian commercial rose production (Blümel et al. 2002). The observed difference in $N$. californicus density between hot-spot greenhouses and conventional greenhouses could be a result of the hot-spot greenhouses being gradually introduced over a period of 1-5 months before the onset of the study period, allowing $N$. californicus to recover in numbers. The density of $N$. californicus in hot-spot treated greenhouses was so high ( 0.05 mites per leaflet) that it can have significantly contributed to spider mite control, making it in theory impossible to ascribe biocontrol to $P$. persimilis ( 0.08 mites per leaflet) alone, but perhaps rather to a combined effect of reduced acaricides input, conserving naturally occurring $N$. californicus, and the effect of hot-spot application of $P$. persimilis. In a study investigating traditional rose production system with a closed canopy, allowing easy dispersal of mites, long-term stability of spider mites and predatory mites was found (Gough 1991). However, modern systems are more intensive, the canopy is more open, and such stability in mite populations is not found. Pesticide use can lead to failure of biological control, and an attempt to demonstrate the effectiveness of $P$. persimilis and $N$. californicus use in commercial greenhouses failed due to the use of pesticides (De Vis and Barrera 1999). In agreement with our findings, an IPM study in roses assessing application of $P$. persimilis based on co-occurrence with spider mites resulted in a good spider mite control (Casey et al. 2007), but lacks pesticide use information. The present study from Kenya demonstrates effective hot-spot management of $T$. urticae in large commercial greenhouses, though having a production plant on the farm that supplies predatory mites at production cost is an exception. Assuming harvested stems were of at least similar quality (data could not be provided due to commercial interests), this demonstrates that it is possible to considerably decrease acaricide use with hot-spot treatments with $P$. persimilis, which is positive as hot-spot treatment provides important benefits economically as well as environmentally and for workers health. Finally, less use of acaricides and a move towards reduced risk pesticides will better protect beneficial species such as
P. persimilis and N. californicus (Nicetic et al. 2001; Numa et al. 2011). However, the system depends on intensive scouting. In countries with higher labour costs, e.g. in Europe, the situation may be different, and such intensive scouting not possible. Future research could further improve the method, and for example studies to establish the needed proportion of $P$. persimilis to $T$. urticae in a hot-spot may help make the use of predators more economically feasible (Park et al. 2000; Hilarion et al. 2008; Alatawi et al. 2011). Likewise, a higher efficiency of $P$. persimilis may be obtained if combined with $N$. californicus (Blümel et al. 2002), and when a more full biological control strategy including biological control of other pests is developed (Casey et al. 2007).

However, hot-spot treatments can only be adopted by farmers if effective relative to conventional (prophylactic, blanket application) applications, hot-spot treatments rely heavily on scouting and monitoring to help detection of pests, and should be based on pest threshold levels, considering threat to the crop, and cost-benefit analysis of the control option (Zehnder et al. 2007). In conclusion, hot-spot treatments allow for large-scale commercial rose production with the same productivity as in conventionally treated roses, while reducing the cost of pest control, particularly by cutting acaricide costs.

Acknowledgments Authors thank Finlays Horticulture Ltd for providing the study site and staff time. Authors also thank DANIDA for financially supporting the study. We thank Dr. Arne Janssen, Dr. Eric Wajnberg and two anonymous reviewers for their constructive comments to previous versions of this paper. Also thanks to Prof. Jacob Weiner, University of Copenhagen for his comments.

\section{References}

Alatawi F, Nechols JR, Margolies DC (2011) Spatial distribution of predators and prey affect biological control of twospotted spider mites by Phytoseiulus persimilis in greenhouses. Biol Control 56:36-42

Attia S, Grissa KL, Lognay G, Bitume E, Hance T, Mailleux C (2013) A review of the major biological approaches to control the worldwide pest Tetranychus urticae (Acari: Tetranychidae) with special reference to natural pesticides. J Pest Sci 86(3):361-386

Blümel S, Walzer A, Hausdorf H (2002) Successive release of Neoseiulus californicus A. H. (Acari: Phytoseiidae) for sustainable biological control of spider mites in greenhouse cut roses -Interim results of a two years study in a commercial nursery. IOBC/WPRS Bull 25(1):21-24 
Bugeme DM, Knapp M, Boga HI, Wanjoya AK, Maniania NK (2008) Influence of temperature on virulence of fungal isolates of Metarhizium anisopliae and Beauveria bassiana to two-spotted spider mite Tetranychus urticae. Mycopathologia 167:221-227

Casey C, Newman J, Robb K, Tjosvold S, Macdonald J, Parrella M (2007) IPM program successful in California greenhouse cut roses. Calif Agric 61(2):71-78

De Vis R, Barrera J (1999) Use of two predators Phytoseiulus persimilis Athias-Henriot (Acari: Phytoseiidae) and Neoseiulus californicus (Mcgregor) (Acari: Phytoseiidae) for the biological control of Tetranychus urticae Koch (Acari: Tetranychidae) in roses in the Bogotá plateau. ISHS Acta Hort 482:259-268

El-Laithy AYM, Sawsan AE (2005) Release of the predatory mites Phytoseiulus persimilis Athias-Henriot and Neoseiulus californicus Mc Gregor to control the two-spotted spider mite Tetranychus urticae Koch infesting cucumber and rose in plastic houses in Egypt. Ann Agric Sci Cairo 50:759-767

Escudero LA, Ferragut F (2005) Life-history of the predatory mites Neoseiulus californicus and Phytoseiulus persimilis (Acari: Phytoseiidae) on four spider mite species and prey, with special reference to Tetranychus evansi (Acari: Tetranychidae). Biol Control 32:378-384

Goka K (1998) The effect of patch size and resistence of host plants on the development of miticide resistance in the twospotted spider mite Tetranychus urticae (Acari: Tetranychidae). Exp Appl Acarol 23:419-427

Gough N (1991) Long-term stability in the interaction between Tetranychus urticae and Phytoseiulus persimilis producing successful integrated control on roses in southeast Queensland. Exp Appl Acarol 12:83-101

HCDA (2009) Horticultural crops development authority. Export statistics by air for flowers, fruits and vegetables. Ministry of Agriculture. Government of Kenya Uniafric, Nairobi

Hilarion A, Niño A, Cantor F, Rodriguez D, Cure JR (2008) Criteria for the release of Phytoseiulus persimilis Athias Henriot. (Parasitiformes: Phytoseiidae) in rose culture. Agron Colomb 26:68-77 (In Spanish with abstract in English)

Holt KM, Opit GP, Nechols JR, Margolies DC, Williams KA (2007) Comparing chemical and biololgical control strategies for twospotted spider mites on mixed plantings of ivy geranium and impatiens. Hort Tech 17:322-327

Insecticide Resistance Action Committee, IRAC. Accessed Nov 2014. http://www.irac-online.org/

Jacobson RJ (1993) Integrated pest management in spring bedding plants: a successful package for commercial crops. IOBC/WPRS Bull 16:105-112

Khajehali J, Van Nieuwenhuyse P, Demaeght P, Tirry L, van Leeuwen T (2011) Acaricide resistance and resistance mechanisms in Tetranychus urticae populations from rose greenhouses in the Netherlands. Pest Manag Sci 67:1424-1433

Knapp M, Sarr I, Gilioli G, Baumgärtner J (2006) Population models for threshold-based control of Tetranychus urticae in small-scale Kenyan tomato fields and for evaluating weather and host plant species effects. Exp Appl Acarol 39:195-212
Nicetic O, Watson DM, Beattie GAC, Meats A, Zheng J (2001) Integrated pest management of two-spotted mite Tetranychus urticae on greenhouse roses using petroleum spray oil and the predatory mite Phytoseiulus persimilis. Exp Appl Acarol 25:37-53

Numa S, Bustos A, Rodríguez D, Cantor F (2011) Laboratory and greenhouse evaluation of the entomopathogenic fungi and garlic pepper extract on the predatory mites, Phytoseiulus persimilis and Neoseiulus californicus and their effect on the spider mite Tetranychus urticae. Biol Control 57:143-149

Opit GP, Nechols JR, Margolies DC (2004) Biological control of two spotted spider mite, Tetranychus urticae (Acari: Tetranychidae), using Phytoseiulus persimilis (Acari: Phytoseidae) on ivy geranium: assessment of predator release ratios. Biol Control 29:445-452

Park J, Kilm Y, Cho K (2000) Application of sequential classification of prey/predator ratio test to Tetranychus urticae and Phytoseiulus persimilis system in greenhouse roses. J Asia-Pacific Entomol 3(2):121-126

SAS Institute Inc. 2008. SAS/STAT ${ }^{\circledR} 9.2$ User's Guide. SAS Institute Inc, SAS Campus Drive; Cary, North Carolina

Stavrinides MC, Nieuwenhuyse P, van Leeuwen T, Mills NJ (2009) Development of miticide resistance in Pacific spider mite (Tetranychus pacificus) from California vineyard. Exp Appl Acarol 50:243-254

van de Vrie, M (1985) Greenhouse ornamentals In: Helle W, Sabelis MW (eds) Spider mites - their biology, natural enemies and control, Vol 1B Elsevier Science Publications, Amsterdam, pp 273-284

Zehnder G, Gurr GM, Kühne S, Wade MR, Wratten SD, Wyss E (2007) Arthropod pest management in organic crops. Ann Rev Entomol 52:57-80

Zhang Z (2003) Mites of greenhouses: identification, biology and control. CABI Publishing, Wallingford

Znaor D, Pretty J, Morrison J, Todorovic SK (2005) Environmental and macroeconomic impact assessment of different development scenarios to organic and low-input farming in Croatia. University of Essex Centre for Environment and Society, UK. http://www.fao.org/docs/eims/upload/ 229899/2005_12_doc02.pdf

Catherine Gacheri has 13 years experience in biological control agents mass production and usage. She is the technical support and sales manager in Dudutech Kenya and leads a technical sales team supporting Kenyan growers on the best integrated pest management approaches.

Thomas Kigen has 11 years experience in mass production of biological control agents, rose production and integrated pest management. He is the technical sales officer at Dudutech Kenya Limited in charge of offering technical advice to Kenyan growers on integrated pest management.

Lene Sigsgaard is associated professor at University of Copenhagen, Denmark and one of her research areas is biological control and integrated pest management. 